\title{
Tumoral response factors after radiofrequency ablation of hepatocellular carcinoma in cirrhotic liver
}

\author{
J. Calleja Kempin, A. Colón Rodríguez, A. Muro de la Fuente ${ }^{1}$, G. Clemente Ricote ${ }^{2}$, M. Prieto Martín”, \\ L. Santos Castro², A. Matilla Peña ${ }^{2}$, R. Bañares Cañizares² and D. Martín Baena
}

General Surgery Department and Liver Transplantation Unit. ${ }^{I}$ Radiology Department. ${ }^{2}$ Gastroenterology Department and Liver Transplantation Unit. Hospital General Gregorio Marañón. Universidad Complutense. Madrid, Spain

\begin{abstract}
Objective: hepatocellular carcinoma ( $\mathrm{HCC}$ ) ablation by radiofrequency (RFA) is a novel technique with a great variety of methods whose efficacy and predictive factors have not been completely studied. Some of the main predictive factors in this type of treatment are analyzed in the present study.

Patients and methods: ninety-three patients with hepatocellular carcinoma over cirrhosis, and with no indication for surgical resection were treated by RFA. Two different types of electrodes were used for RFA (refrigerated-"Cool-Tip" and perfusion with saline solution, the approach was percutaneous, by laparoscopy or laparotomy.

Results: overall survival at 1,2 and 3 years was 88,81 , and $76 \%$, with a free-disease survival (FDS) of 66, 31 and 17\%, respectively. For tumors less than $3 \mathrm{~cm}$, FDS at 1,2 and 3 years was 74,44 and $30 \%$, while for more than $3 \mathrm{~cm}$ in size FDS was 55 , 12 and $0 \%(p=0.02)$. FDS for HCC with one nodule was 70, 36 and $22 \%$, and for more than one nodule it decreased to 50, 17 and $0 \%$ at 1,2 and 3 years, respectively ( $p=0.07)$. Surprisingly, the method employed for RFA has a main influence in FDS, with $0 \%$ at 3 years for perfusion electrodes and 26\% for cool-tip electrodes at the same period.

Conclusions: in this series, overall survival at three years was relatively high; however, tumoral size, number of nodules and RFS method were independent variables associated with diseasefree survival.
\end{abstract}

Key words: Tumoral ablation. Radiofrequence. Hepatocarcinoma. Hepatic cirrhosis.

Calleja Kempin J, Colón Rodríguez A, Muro de la Fuente A, Clemente Ricote G, Prieto Martín M, Santos Castro L, Matilla Peña A, Bañares Cañizares $R$, Martín Baena D. Tumoral response factors after radiofrequency ablation of hepatocellular carcinoma in cirrhotic liver. Rev Esp Enferm Dig 2005; 97: 688-698.

Recibido: 03-01-05.

Aceptado: 10-05-05.

Correspondencia: Javier Calleja Kempin. Departamento de Cirugía General y Unidad de Trasplante Hepático. Hospital General Universitario Gregorio Marañón. C/ Dr. Esquerdo, 46. 28007 Madrid

\section{INTRODUCTION}

Hepatocellular carcinoma (HCC) over a cirrhotic liver could be the natural evolution of advanced chronic liver conditions. This fact may preclude some therapeutic decisions, not only in relation to tumoral extension but also to functional status and portal hypertension. On the other hand, the natural evolution of the asymptomatic group of patients with this condition has long survival rates (1). All these facts lead to individualized therapeutic decisions in every case.

There are many CHC therapies, some with curative intention (liver transplantation, surgical resection, ablation techniques), and some with palliative aims (chemoembolization). Liver transplantation (TH) offers best results in a selected group of patients $(2,3)$, but this technique is limited by factors such as age, associated diseases, and other formal contraindications. Surgical resection is also precluded by functional status and portal hypertension, as commented upon before, with a relatively low applicability in the whole hepatocellular group of patients $(4,5)$. Ablation techniques by alcohol injection, radiofrequency and other methods $(6,7)$ had increased curative possibilities during the last decade. A recent controlled study (8) has shown that radiofrequency ablation (RFA) is superior to alcohol injection in terms of tumoral recurrence and survival in CHCs of $4 \mathrm{~cm}$ or less; however, not all the determinant factors of the technique are completely understood. The main objective of the present study is to analyze predictive factors of tumoral response after RFA.

\section{MATERIAL AND METHODS}

\section{Patient groups}

Ninety patients diagnosed with HCC complicating liver cirrhosis that were treated between June 1999 and June 
2004 using RFA. HCC was diagnosed by percutaneous fine-needle aspiration puncture in 70 cases, and by three coincidental image studies (US, CT-scan, MRI) in the remaining cases. The diagnosis of liver cirrhosis was obtained by liver biopsy or clinical, biological, and radiological criteria.

Curative RFA was attempted in patients not eligible for liver resection (LR) or liver transplantation (LT). The Barcelona Clinic Liver Cancer Staging Classification (9) criteria were used for the indication of surgical or alternative techniques. By these criteria hepatectomy was only performed when a tumor nodule smaller than $5 \mathrm{~cm}$ in diameter or a maximum of three nodules smaller than $3 \mathrm{~cm}$ with a portal pressure below $10 \mathrm{mmHg}$ and Child A status were present. Patients eligible for LT were those with tumor diameters smaller than $5 \mathrm{~cm}$ or three nodules below $3 \mathrm{~cm}$ and age younger than 68 years, with functional status $\mathrm{B}$ or $\mathrm{C}$ and no comorbidity.

\section{RFA methods}

Two different radiofrequency systems were employed depending on hospital supply in every period. In the first group of patients a "Cool-Tip" radiofrequency electrode (Radionics) was used. This electrode has an internal refrigeration system using cold distilled water, and a generator operating with $480 \mathrm{kHz}$ currents and a maximum power output of $200 \mathrm{~W}$. This technology was used to treat the first 44 cases (47.3\%) from June 1999 to April 2001.

From April 2001 to June 2004 technology was switched to a Berchtold Medical Electronics electrode. Each electrode had an exposed $2.5 \mathrm{~cm}$-long active tip with eight side holes and no terminal hole, large selfsticking dispersive nickel plate electrodes, and an infusion pump for injecting saline solution through the electrode holes. A computer-supported high-frequency generator of sinusoidal unmodulated high-frequency voltages, and currents of $375 \mathrm{KHz}$ with a maximum power output of $60 \mathrm{~W}$ (Elektrotom 106 HF-Thermo, Berchtold Medizin-Elektronik Tttlingen). This technology was used to treat 49 patients $(52.7 \%)$ during the period mentioned before.

Every procedure was performed in an operating room under anesthesiological monitorization. The RFA approach was selected depending on the anatomical location of the tumor and the radiological window for puncture. Local anaesthesia and sedation was used in 55 cases (59\%) (all percutaneous cases), and general anaesthesia was used in the remaining 38 cases $(41 \%)$. Ten patients with a very good clinical status underwent the procedure on an inpatient basis (percutaneously).

Tumor location for RFA was establihed using US (Toshiba Corevision equipment) in every case, with a US 3.5-MHz perforated linear transducer (Toshiba) for percutaneous procedures, a laparoscopic 5-MHz linear multifrequency transducer with flexible tip (Toshiba) for la- paroscopic procedures, and a $5-\mathrm{MHz}$ multifrequency convex transducer (Toshiba) for laparotomic procedures.

\section{Follow-up}

Patient follow-up was achieved by ultrasonography and CT-scans in every case, and additionally by magnetic resonance imaging (MRI) when no conclusive information was provided by the previous studies. The first follow-up control was at 6 to 8 weeks after RFA, and every 4 months thereafter.

Incomplete treatment was considered when the first monitoring examination showed contrast uptake in the tumor or its vicinity (same segment), while recurrence was considered when, after a first negative control, there was a following positive control. Tumor progression was defined when new tumor nodules were detected in segments other than the one with the treated primary nodule at follow-up. In case of multicentric progression with more than 3 nodules a new RFA was not considered and a palliative treatment was planned.

\section{Statistical analysis}

The endpoint of the study was the time free of HCC disease (recurrence or progression). Kaplan-Meier analyses were performed for the assessment of survival, time of recurrence or time until progression, and functions of survival were compared using Breslow's test. P values $<0.05$ were considered statistically significant.

For the evaluation of independent predictive variables associated with the endpoint a Cox proportional hazard model was developed. Continuous variables were introduced as dicotomic variables according to median value. Only variables with a p-value less than 0.1 in univariate analyses, and those clinically relevant were included in the model. Results were expressed as HR with its corresponding 95\% confidence interval. Presumption of proportional risks was evaluated by inclusion in a continuous-variable time-dependent model (obtained by natural time logarithm product and covariables with a p-value less than 0.1 in univariate analyses). The model was developed according to maximum verisimilitude method.

\section{RESULTS}

Patient epidemiological data are summarized in table I. A total of 158 RFA sessions were performed for 93 patients [mean of 1.7 per patient (0.3)]. Mean duration of RFA was 15.3 (6.7) minutes. The characteristics and location of tumors, and RFA approaches are detailed in table II.

Every patient with uninodular tumors in a Child A status showed portal hypertension, detected by HVPG over 
Table I. Demographic and clinical characteristics of patients treated using RFA. Results are expressed as number (percentage) for qualitative variables, and as mean value (DE) for quantitative variables

\begin{tabular}{ll}
\hline Variable & \\
\hline Sex (male) & $73(78.5)$ \\
Age & $66(10.4)$ \\
Etiology of cirrhosis & \\
Hepatitis VHC & $59(63.4)$ \\
Alcohol abuse & $17(18.3)$ \\
Hepatitis B & $7(7.5)$ \\
Hepatitis C and alcohol abuse & $5(5.4)$ \\
Other causes & $5(5.4)$ \\
& \\
Functional status (Child-Pugh) & $74(79.6)$ \\
A & $18(19.4)$ \\
B & $1(1.1)$ \\
C & \\
\hline
\end{tabular}

Table II. Characteristics of tumors treated using RFA. Results are expressed as number (percentage) for qualitative variables, and as mean value (DE) for quantitative variables

\begin{tabular}{|c|c|}
\hline Characteristic & \\
\hline \multicolumn{2}{|l|}{ Nodularity } \\
\hline Uninodular tumor & $75(80.6)$ \\
\hline Multinodular tumor (2 or 3 nodules) & $18(19.4)$ \\
\hline \multicolumn{2}{|l|}{ Tumor localization } \\
\hline Right lobe & $58(63)$ \\
\hline Left lobe & $27(29)$ \\
\hline Bilobar & $8(8)$ \\
\hline Tumor size & $3.04(1.18)$ \\
\hline \multicolumn{2}{|l|}{ Therapeutical approach } \\
\hline Percutaneous & $63(67.7)$ \\
\hline Laparoscopic & $17(18.3)$ \\
\hline Laparotomic & $12(12.9)$ \\
\hline
\end{tabular}

$10 \mathrm{mmHg}$ or evident signs of portal hypertension (esophageal varices or portal collaterals in CT-scans).

RFA was adequate with a first negative control in 75 cases $(80 \%)$, while recurrence or progression during follow-up was detected in 54 cases $(58.1 \%)$. Overall survival at 1.2 and 3 years was 88,81 and $76 \%$, respectively (Fig. 1), with a median follow-up (range) of 469 (6-1851) days. However, the cumulative probability of diseasefree survival (lack of recurrence, progression, or both) was 66,31 and $17 \%$ at 1,2 and 3 years, respectively (Fig. 2). A univariate analysis did not show significant differences in disease-free survival (DFS) regarding age (more or less than 69 years), sex, Child's status or RFA-approach. DFS for tumors with a diameter of $3 \mathrm{~cm}$ or less

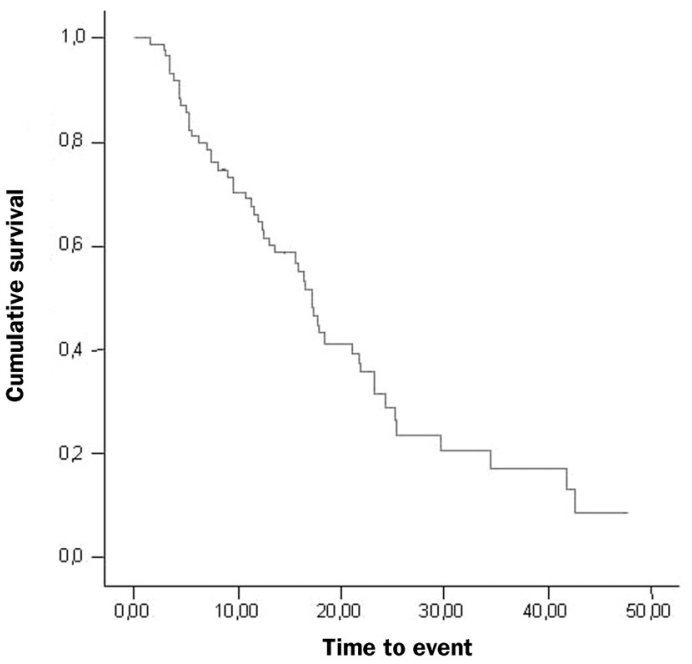

Fig. 1.- Disease-free survival (months). Supervivencia libre de enfermedad (meses).

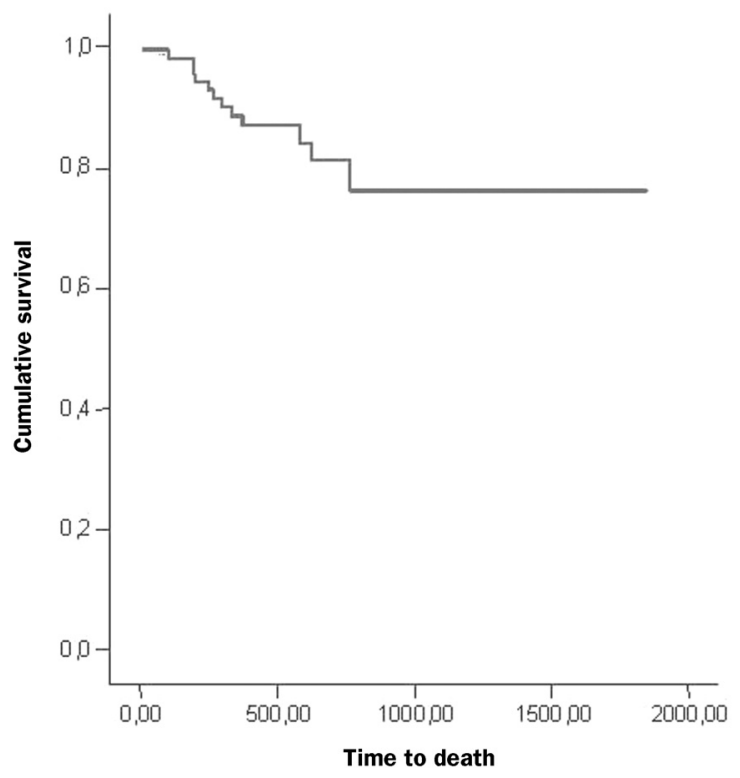

Fig. 2.- Overall survival after RFA (days). Supervivencia global tras ARF (días).

was 74, 44 and $30 \%$ at 1, 2 and 3 years, significantly superior to that for tumors greater than $3 \mathrm{~cm}$ in size, which was 55, 12 and $0 \%(\mathrm{p}=0.02$; Fig. 3). Similarly, DFS was higher for one-nodule tumors when compared to two- or three-nodule tumors (70, 36 and $22 \%$ vs. 50,17 and $0 \%$ at 1,2 and 3 years, respectively; $p=0.07$, Fig. 4). Finally, the electrode type had a radical importance in DFS. In this sense, patients treated with "cool-tip" electrodes had better DFS than those treated with perfusion electrodes (80, 43 and $26 \%$ vs. 49,12 and $0 \%$ at 1,2 and 3 years, respectively; $\mathrm{p}=0.02$; Fig. 5). Cox's risk proportional 


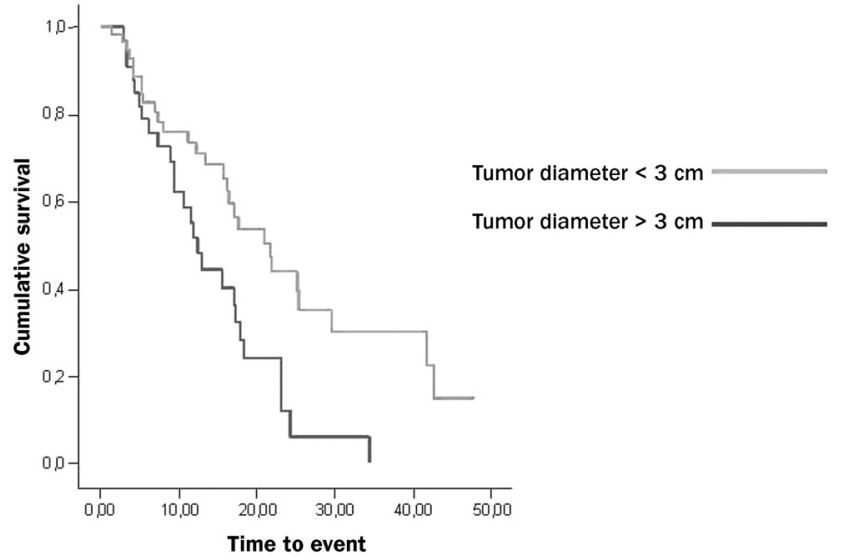

Fig. 3.- Survival according to tumor diameter (months). Supervivencia según diámetro tumoral (meses).

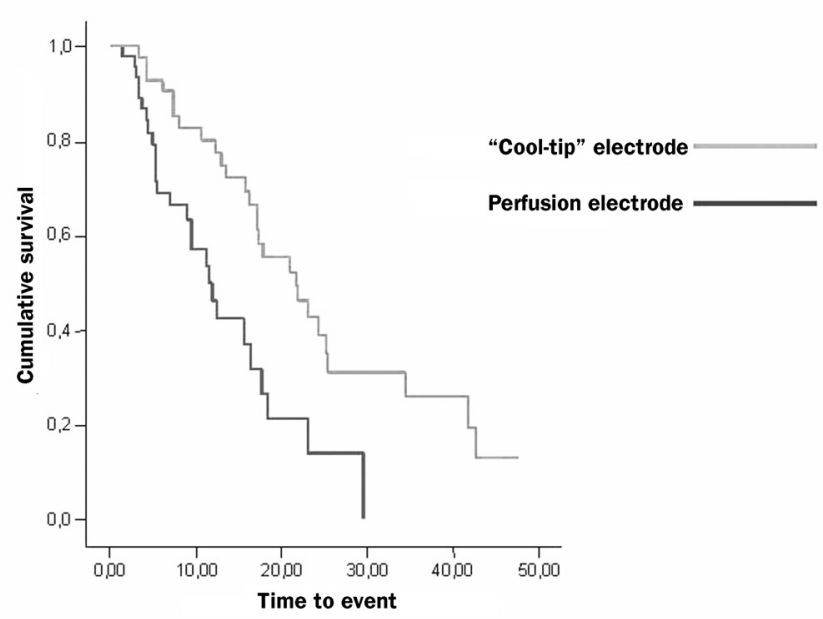

Fig. 5.- Survival according to electrode type (months). Supervivencia según el tipo de electrodo utilizado (meses).

model showed that tumor size, number of nodules, and electrode type were independent variables associated with DFS (Table III).

The ablative procedure was completed during the first session in 91 cases $(97.8 \%)$. There were 9 intraoperative complications $(9.6 \%)$, corresponding to severe pain in 5 cases (local anesthesia), arrhythmia in 2 (interruption of procedure), and tumor disruption in a peripheric nodule requiring laparotomy and surgical hemostasis; finally, one patient developed self-controlled hemobilia. The two patients who showed arrhythmia during the RFA procedure were treated satisfactorily some days later.

Most frequent symptoms following this procedure included different intensity pain in 20 cases $(22 \%)$ and fever in 15 cases (16\%), mostly treated with antibiotics and analgesics, although the most probable origin was tumor necrosis. Other morbidity was asymptomatic pleural effusion in 9 cases $(9.6 \%)$, mild skin burning near the radiofrequency plaque in $6(6.4 \%)$, postoperative ascites

Fig. 4.- Survival according to nodule counts (months). Supervivencia según el número de nódulos (meses).

Table III. Cox proportional hazards model results

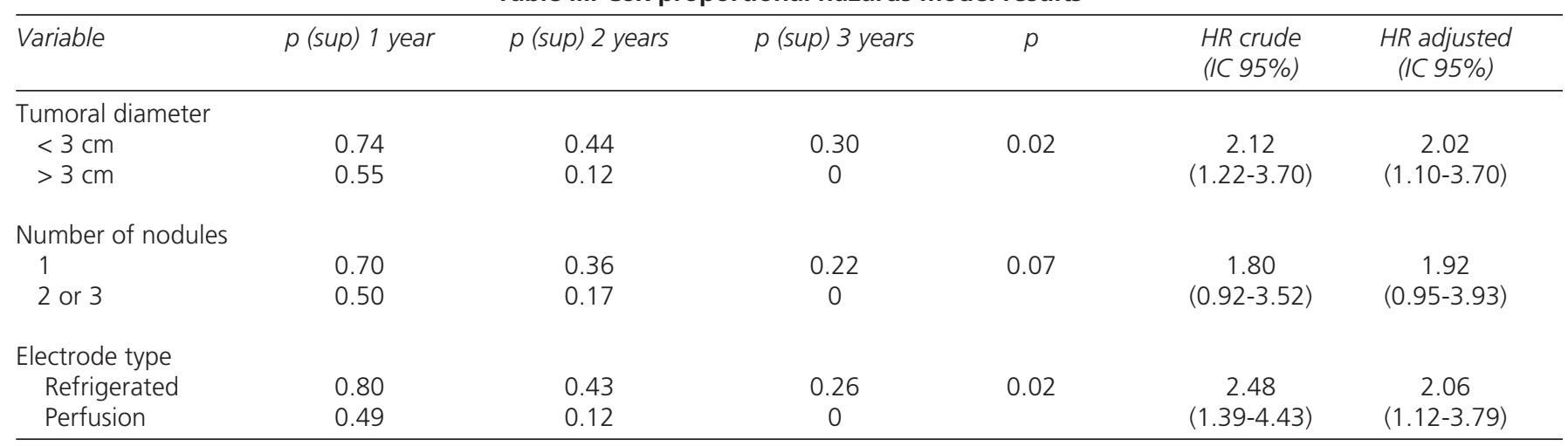


that was easily treated in 5 patients $(5.3 \%)$, and colonic perforation seven days after treatment (after patient discharge), with subsequent death in one case (after a laparotomy in another hospital). However, there was only one case of hemobilia, while $2 \mathrm{HCC}$ were in contact with the gallbladder and a few more were near the major hepatic ducts. Two patients died before discharge $(2.1 \%)$, one from multiple organ failure after surgical RFA $(5 \mathrm{~cm}$ in diameter), and one from hemorrhage after diaphragmatic injury by the electrode.

Six patients were transplanted after the RFA procedure, two of them showed complete tumor necrosis in one liver sample, and partial necrosis in variable degrees in the rest.

\section{DISCUSSION}

$\mathrm{HCH}$ is considered by many authors a part of the natural history of liver cirrhosis. $\mathrm{HCH}$ risk is about $3 \%$ per year, increasing to $5 \%$ in case of VHC infection (10). Nowadays, surgical resection and liver transplantation are considered the most effective techniques $(2-5,11)$; however, many factors can preclude their performance $(10,12)$, as was commented on before. In this sense, some new types of HCC treatment with curative intention had been developed -these include local ablative therapies. RFA was developed as a local therapy with a wide application margin and low aggression for the patient. Hence, this therapy could reduce morbidity and mortality, thus reducing costs and increasing the cost-efficacy rate, which permits inpatient treatment in a vast group of such patients (13).

Results in the present study confirm acceptable survival rates with more than $70 \%$ at three years in a wide and homogeneous group of patients; however, the probability of DFS has been very limited. Nevertheless, it is important to remark that this group of patients is not strictly comparable to that of surgically-treated patients, because of a negative selection in the RFA group $(4,5,14)$. On the other hand, although chemoembolization showed increased survival in extensive HCC not eligible for curative treatment, results are not comparable to those of RFA-treated patients because of marked differences between patient characteristics in both groups (15).

In this experience, tumor size, presence of more than one nodule, and surprisingly type of electrode were independently associated with low DFS (16), which was not related to a high rate of initial response similar to that obtained in most series (17). Regarding the first two factors, while the literature shows great variability, there is a strong tendency to consider these factors mainly responsible for the efficacy of treatment (18-24).

However, electrode type has never been described as a main factor in the efficacy of RFA by other authors. Giorgio et al. (16), using the same electrode in a short followup study, did not find unfavorable results. Thus, that ob- servation leads to an analysis of electrode type as a variable in RFA results.

Postoperative morbidity-mortality was low in most of the series $(8,24-28)$, and related to patient selection and learning curve, which may also influence tumor recurrence (29). Many studies show no mortality and low morbidity; in 41 hospitals in Italy, mortality was $0.3 \%$, with a morbidity rate of $7.1 \%$ (30), figures that are similar to those obtained by Curley in a 608-patient series treated in the same center (26). A good coordination between hepatologists, radiologists and surgeons was the key point of our study. As a matter of fact, we did not observe significant technical complications during the study that might have precluded treatment. The fact that there were no important vascular or biliary complications, even after RFA of tumors adjacent to major structures, including the gallbladder, is remarkable (31). However, it is important to point out a high risk of perforation if the tumor is in the vicinity of hollow viscera, specially the large bowel; this complication developed in one patient who died at the seventh day after the RFA procedure, and has also been described by other authors $(25,32)$.

No neoplastic dissemination along the electrode target was observed in our series; nevertheless, Llovet et al. acknowledged $12.5 \%$ in their experience (33). Many other authors observed this complication arising at a rate between 0 and $2.8 \%$ (34-36).

The high rate of tumor control after 12 months, with low morbidity and mortality, shows that RFA is a good therapy for cancer patients in the liver transplantation waiting list. In this sense, a high necrosis rate of HCC was described in specimens after liver transplantation, a figure similar to data published by Fontana et al. (37) and Mazaferro et al. (38).

Although RFA has been insufficiently studied to this day (39), these results suggest that it is a safe and reliable technique, with better results than chemo-embolization (40) or even ethanol injection (41). However, different factors such as size bigger than $3 \mathrm{~cm}$ and multinodularity affect the results radically. Finally, the radiofrequency electrode may also alter the ablation rate and has to be evaluated when more than one electrode has been employed.

\section{REFERENCES}

1. Llovet JM, Bustamante J, Castells A, Vilana R, Ayuso MC, Sala M, et al. Natural history of untreated nonsurgical hepato-cellular carcinoma: rationale for the desing and evaluation of therapeutic trials. Hepatology 1999; 29: 62-7.

2. Bismuth H, Chiche L, Adam R, Castaign D, Diamond T, Dennison A. Liver resection versus transplantation for hepatocellular carcinoma in cirrhotic patients. Ann Surg 1993; 218: 145-51.

3. Mazzaferro V, Regalia E, Doci R, Andreola S, Pulvirenti A, Bozzetti F, et al. Liver transplantation for the treatment of small hepatocellular carcinomas in patients with cirrosis. New Engl J Med 1996; 334: 693-9.

4. Fuster J, García-Valdecasas JC, Grande L, Tabet J, Bruix J, Anglad T, et al. Hepatocellular carcinoma and cirrhosis: results of surgical treat- 
ment in a European Series. Ann Surg 1996; 223: 297-302.

5. Figueras J, Jaurrieta E, Valls C, Ramos E, Serrano T, Rafecas A, et al. Resection or transplantation for hepatocellular carcinoma in cirrhotic patients: outcomes based on indicated treatment strategy. J Am Coll Surg 2000; 190: 580-7.

6. Rossi S, Di Stasi M, Buscarini E, Quaretti P, Garbagnati F, Squassante L. Percutaneous interstititial thermal ablation in the treatment of hepatic cancer. Am J Roentgenol 1966; 167: 759-68.

7. Solbiati L, Goldberg SN, Ierace T, Livraghi T, Meloni F, Dellanoce M. Hepatic metastasis: percutaneous radio-frequency ablation with cool-tip electrodes. Radiology 1997; 205: 367-73.

8. Shi-Ming L, Chun-Jung L, Chen-Chun L, Chao-Wei H, Yi-Cheng C. Radiofrequency ablation improves prognosis compared with ethanol injection for hepatocellular carcinoma $<4 \mathrm{~cm}$. Gastroenterology 2004; 127: 1714-23.

9. Llovet JM, Brú C, Bruix J. Prognosis of hepatocellular carcinoma. The BCLC staging classification. Semn Liver Dis 1999; 19: 329-38.

10. Donckier V, Van Laethem JL, Van Gansbeke D, Ickx B, Lingier P, Closset J, et al. New considerations for an overall approach to treat hepatocellular carcinoma in cirrhotic patients. J Surg Oncol 2003; 84: 36-44.

11. Biogourdan JM, Jaek D, Meyer N, Meyer C, Oussoultzogloun E, Bach P, et al. Small hepatocellular carcinoma in Child A cirrhotic patients: hepatic resection versus transplantation. Liver Transpl 2003; 9: 513-20.

12. Bruix J, Castels A, Bosch J, Feu J, Fuster J, García-Pagan JC, et al. Surgical resection of hepatocellular carcinoma in cirrhotic patients: prognostic value of preoperative portal pressure. Gastroenterology 1996; 111: 1018-23.

13. McGahan, Dodd III GD. Radiofrequency ablation of the liver: current status. AJR 2001; 176: 3-16.

14. Vivarelli M, Guglielmi A, Ruzzanente A, Cucchetti A, Bellusci R, Cordiano C, et al. Surgical resection versus percutaneous radiofrequency ablation in the treatment of hepatocellular carcinoma on cirrhotic liver. Ann Surg 2004; 204: 102-7.

15. Llovet JM, Bruix J. Systematic review of randomised trials for unresectable hepatocellular carcinoma:chemoembolization improves survival. Hepatology 2003; 37: 429-42.

16. Giorgio A, Tarantino L, de Stefano G, Scala V, Liorre G, Scarano F, et al. Percutaneous sonographically guided saline-enhanced radiofrequency ablation of hepatocellular carcinoma. AJR 2003; 181: 479-84.

17. Curley SA, Izzo F, Ellis LM,Vauthey JN, Vallone P. Radiofrequency ablation of hepatocellular cancer in 110 patients with cirrhosis. Ann Surg 2000; 232: 381-91.

18. Izumi N, Ashaina Y, Noguchi O, Uchiara M, Kanazawa N, Itakura J, et al. Risk factors for distant recurrence of hepatocellular carcinoma in the liver after complete coagulation by microwave or radiofrequency ablation. Cancer 2001; 91: 949-56.

19. Bonny C, Abergel A, Gayard P, Chouzet S, Ughetto S, Slim K, et al. Radiofrequency ablation of hepatocellular carcinoma in patients with cirrhosis. Gastroenterol Clin Biol 2002; 26: 735-41.

20. Horiike N, Iuchi H, Ninomiya T, Kawai K, Kumagi T, Michitaka K, et al. Influencing factors for recurrence of hepatocellular carcinoma treated with radiofrequency ablation. Oncol Rep 2002; 1059-62.

21. Guglielmi A, Ruzzenente A, Battocchia A, Tonon A, Fracastoro G, Cordiano C. Radiofrequency ablation of hepatocellular carcinoma in cirrhotic patients. Hepatogastroenterology 2003; 50: 480-4.

22. Komorizono Y, Oketani M, Sako K, Yamasaki N, Shibatou T, Maeda $\mathrm{M}$, et al. Risk factors for local recurrence of small hepatocellular carcinoma tumors after a single application of percutaneous radiofrequency ablation. Cancer 2003; 97: 1253-62.

23. Giovannini M, Moutardier V, Danisi C, Bories E, Pesenti C, Delpero
JR. Treatment of hepatocellular carcinoma using percutaneous radiofrequency thermoablation: results and outcomes in 56 patients. Gastrointest surg 2003; 7: 791-6.

24. Omata M, Tateishi R, Yoshida H, Shiina S. Treatment of hepatocellular carcinoma by percutaneous tumoral ablation methods: Etanol injection therapy and radiofrequency ablation. Gastroenterology 2004; 127 (5 Supl. 1): S159-66.

25. de Baere T, Risse O, Kuoch V, Dromain C, Sengel C, Smayra T, et al. Adverse events during radiofrequency treatment of 582 hepatic tumors. AJR 2003; 181: 695-700.

26. Curley SA, Marra P, Beaty K, Ellis LM, Vauthey JN, Abdalla EK, et al. Early and late complications after radiofrequency ablation of malignant liver tumors in 608 patients. Ann Surg 239; 4: 450-8.

27. Mulier S, Mulier P, Ni Y, Miao Y, Dupas B, Marchal G, et al. Complications of radiofrequency coagulation of liver tumours. British J Surg 2002; 89: 1206-22.

28. Giorgio A, Tarantino L, de Stefano G, Coppola C, Ferraioli G. Complications after percutaneous saline-enhaced radiofrequency ablation of liver tumours: 3- year experience with 336 patients in a single center. AJR 2005; 184: 207-11.

29. Poon RT, Ng KK, Lam CM, Ai V, Yuen J, Fan ST, et al. Learning curve for radiofrequency ablation of liver tumors. Prospective analysis of initial 100 patients in a tertiary institution. Ann Surg 2004; 239: 441-9.

30. Livraghi T, Solbiati L, Meloni MF, Gazelle GS, Halpern EF, Goldberg SN, et al. Treatment of focal liver tumors with percutaneous radio-frequency ablation: complications encountered in a multicenter study. Radiology 2003; 226: 441-51.

31. Patti JW, Neeman Z, Wood BJ. Radiofrequency ablation treatment in proximity to the gallbladder without subsequent acute cholecistitis. Cardiovasc Intervent Radiol 2003; 26: 413-5.

32. Meloni MF, Goldberg SN, Moser V, Piazza G, Livraghi T. Colonic perforation and abscess following radiofrequency ablation treatment of hepatoma. Eur J Ultrasound 2000; 15 (1-2): 73-6.

33. de Sio I, Castellano L, De Girolamo V, di Santolo SS, Marone A, Del Vecchio, et al. Tumor dissemination after radiofrequency ablation of hepatocellular carcinoma. Hepatology 2001; 34: 609-10.

34. Goldberg SN, Solbiati L. Tumor dissemination after radiofrequency ablation of hepatocellular carcinoma. Hepatology 2001; 34: 609.

35. Livraghi $\mathrm{T}$. Tumor dissemination after radiofrequency ablation of hepatocellular carcinoma. Hepatology 2001; 34: 608-9.

36. Bolondi L, Gaiani S, Celli N, Piscaglia F. Tumor dissemination after radiofrequency ablation of hepatocellular carcinoma. Hepatology 2001; 34: 608

37. Fontana RJ, Hamidullah H, Nghiem H, Greeson JK. Percutaneous radiofrequency thermal ablation of hepatocellular carcinoma: a safe and effective bridge to liver transplantation. Liver Transplant 2002; 1165-74.

38. Mazzaferro V, Battiston C, Perrone S, Pulvirenti A, Regalia E, Romito $\mathrm{R}$, et al. Radiofrequency ablation of small hepatocellular carcinoma in cirrhotic patients awaiting liver transplantation. A prospective study. Ann Surg 2004; 240: 900-9.

39. Galandi D, Antes G. Radiofrequency thermal ablation versus other interventions. Cochrane Database Syst. Rev 2002; 3: CD003046.

40. Hsieh CB, Chang HM, Chen TW, Chen CJ, Chan DC, Yu JC, et al. Comparison of transcatheter arterial chemoembolization, laparoscopic radiofrequency ablation, and conservative treatment for decompensated cirrhotic patients with hepatocellular carcinoma. World J Gastroenterol 2004; 10: 505-8.

41. Livraghi T, Goldberg SN, Lazzaroni S, Meloni F, Solbiati L, Gazelle GS, et al. Small hepatocellular carcinoma: treatment with radiofrequency ablation versus ethanol injection. Radiology 1999; 210: 655-61. 